\title{
3D OBJECT RECONSTRUCTION IN A PRE-DIGITAL ERA: CASE STUDY IN THE HISTORY OF RESTORATION
}

\author{
Anna Lobovikov-Katz* \\ Faculty of Architecture and Town Planning, Technion - Israel Institute of Technology, Technion City, Haifa 3200003, Israel - \\ anna@technion.ac.il
}

KEY WORDS: Restoration, Reconstruction, 3D Object, History of Restoration, Geometry, Technology, Material Restoration

\begin{abstract}
:
Restoration of the ensemble of parks, palaces and fountains of Peterhof (Petrodvorets) near St. Petersburg (Leningrad), Russia, is one of world-renowned restoration projects of the post - World War II period. However, little has been analysed of this unique restoration experience. This paper presents a specific episode in the history of this restoration project.

The Peterhof ensemble is a complex historic site which includes many palaces, structures and fountains covering $18 \mathrm{square} \mathrm{km}$ of parks and gardens. The Grand Palace, - the central and the largest building of this ensemble, was built at the edge of a natural terrace, with a view to the sea (the Gulf of Finland) and the Lower Park at the foot of the terrace. This dominant spatial-architectural role of the Grand Palace was emphasized by its highest elements - two cupolas of its eastern and western parts. The cupolas were heavily damaged during World War II and shape reconstruction had to be undertaken for their restoration. The restoration of cupolas was one of the first and important steps in the restoration of the Peterhof ensemble.

This paper focuses on the approach, methodology and the selected technological aspects of the restoration of cupolas of the Grand Palace, with a view to their interpretation at the time of restoration of cupolas (1950-s) as well as to modern restoration principles. It shows the process and methods of non-digital reconstruction of the shape of 3D object aided by non-digital models, unique decisions and techniques.
\end{abstract}

\section{INTRODUCTION}

\subsection{Historical background}

The Peterhof ensemble of parks, palaces and fountains was initiated at the beginning of $18^{\text {th }}$ century as a small house for an emperor - Peter the Great (Izmailov, 1909). Already in the first quarter of the century, in the lifetime of its founder, it was significantly extended: the Lower and the Upper parks were laid out according to the plans drafted by the emperor (which might explain for some irregularities of their otherwise symmetrical layouts); the Grand Palace and the Grand Cascade with its landscape and fountains design were formulated, and the small palaces of Marli, Monplaisir and Hermitage were constructed, as well as other pavilions, fountains and cascades. Many renowned architects, artisans and artists from Russia and other countries contributed to construction of the Peterhof ensemble.

The memory of Peter the Great preserved through the centuries the core buildings and their parts which were directly connected with his name. However, on a larger scale, palaces, and especially the Grand Palace, underwent partial redesign in order to suit the taste of the subsequent Russian emperors. The most dramatic transformation of the Grand Palace took place under the empress Elisabeth I, who commissioned the architect of Italian origins, Francesco Bartolomeo Rastrelli, to extend a relatively small palace to its present 300 meters long building. Rastrelli's design of the palace was culminated with cupolas on its both flanks -the East and the West. As typical of Russian baroque - the style which he invented and introduced into Russian architecture, - Rastrelli's design was a strictly symmetrical composition. However, the Empress added four more cupolas over the Eastern part, which contained a court church - to make it similar to the traditional five-cupola scheme of Russian churches. The architect had no choice but to comply with the Imperial order. Therefore, before their destruction during the World War II, the cupolas looked different.

\subsection{The destruction}

During World War II and the siege of Leningrad Peterhof (Petrodvorets) was occupied by Nazi troops. At the same time, a small adjacent territory to the West remained under the Soviet army control. This specific situation caused especially severe battles in and around the ensemble of parks and loss of human lives.

Parks, buildings and fountains were severely damaged. Some part of the works of art were evacuated before the occupation. Many sculptures from the Lower Park stayed hidden in the ground through the years of occupation, and some structures remained in a good condition. However, overall scope of damages was very extensive (Fig. 1).

\subsection{Restoration background}

St Petersburg was initiated in the beginning of the $18^{\text {th }}$ century according to a plan by the French landscape architect Le Blond (Michailov, 1963). Building regulations contributed further to overall architectural harmony of the city image, e.g. through a control of proportions of streets; height of buildings; recommended colours of facades, design of embankments and bridges over rivers and canals etc. Many renowned Russian and European architects and artists contributed to architectural and

\footnotetext{
* Corresponding author
} 
artistic values of buildings and architectural ensembles of the city for more than two centuries.

The unique architectural character of the city, the vast scope of damage and destruction to its architectural heritage during the WWII, historical, social, political and other reasons called for urgent restoration of the numerous historic buildings and sites of the city. This brought about the establishment of a unique restoration organization - Special Scientific-Production Restoration Workshops (SSPRW). It consisted of a scientificresearch department, where research was held before actual restoration intervention on each specific object, research on specific problems or materials, etc.; and of a production department which carried out all restoration works in Leningrad and the surrounding area. This structure allowed for a high level of accuracy both of pre-restoration investigation, and of restoration interventions. Quality control and supervision of restoration works were provided by experts of this and other organizations in the city.

\subsection{Restoring Peterhof}

Among many questions in each restoration project (e.g. old versus new uses, maintenance and management, etc.), the following are the most crucial and should be answered before the initiation of a project:

1. Physical state of a building

2. Availability of documentation before the damage

3. Availability of original technologies/materials

4. Availability of conservation technologies/materials

5. Availability of skilled human resources

6. Budget availability

For Peterhof, the answers are shown in Table 1.

\begin{tabular}{|l|c|c|}
\hline \multirow{2}{*}{ Aspect } & \multicolumn{2}{|c|}{ Analysis } \\
\cline { 2 - 3 } & + & - \\
\hline & & \\
Physical state & & $?$ \\
Documentation & $\mathrm{X}$ & \\
Original technology/materials & $\mathrm{X}$ & \\
Conservation technology/materials & $?$ & \\
Skilled human resources & $\mathrm{X}$ & \\
Budget & $\mathrm{X}$ & \\
\hline
\end{tabular}

Table 1. Peterhof: restoration feasibility analysis

As shown in Table 1, Peterhof restoration was in a favourable situation on almost all points with the exception of a very important one - its physical condition, because of the scope of its damage. In general, the sources of visual information were photo documentation; artistic images by artists; historic drawings; measurements of the original objects. For some objects the original plans and facades remained preserved in archives. More information could be gleaned from the maintenance guides, reports and other historical documents.

Materials and technologies were researched, reconstructed or developed by experts of SSPRW. Human resourses involved skilled artists, architects, sculptors and craftsmen of SSPRW. However, some types of restoration technologies or restoration objects required for a targeted training of restoration masters and depended on the success of pre-restoration research findings and development.

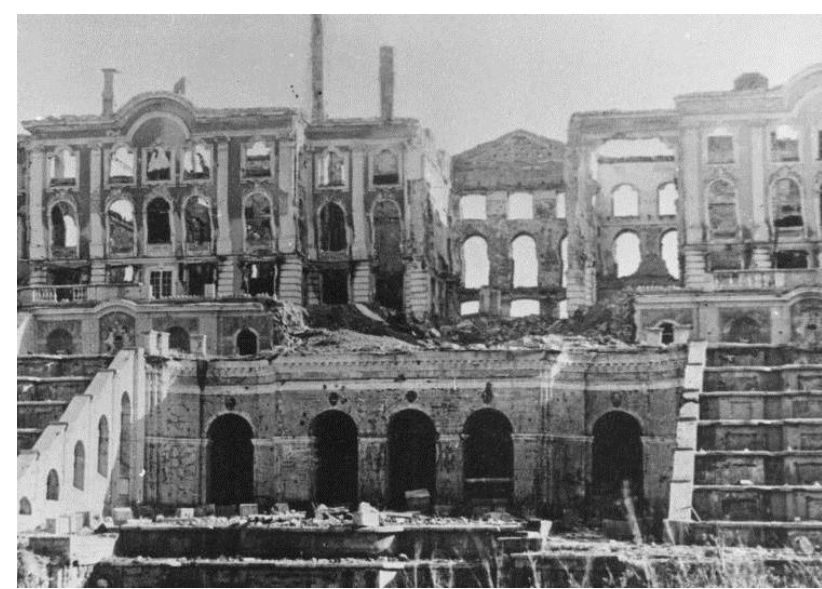

Figure 1. Central part of the Grand Palace and the Grand Cascade of Peterhof after the damages of WWII. (c) Boris Lobovikov archive

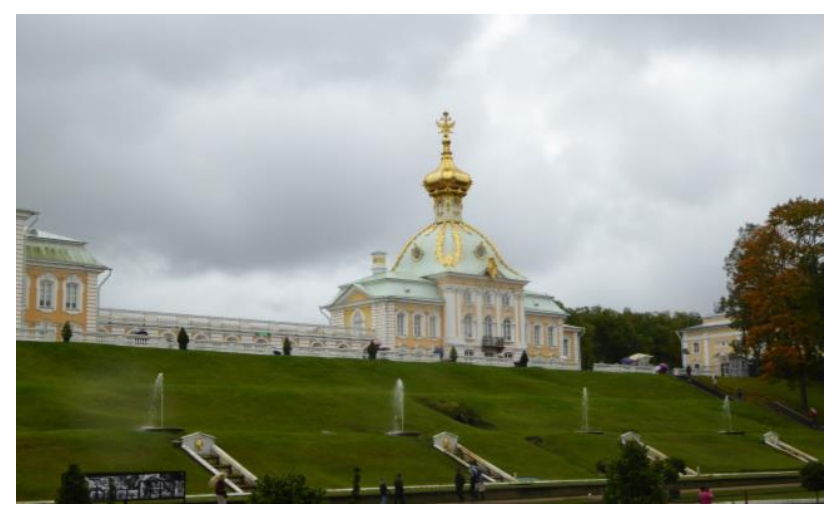

Figure 2. Present day state of cupola and the dome of the Western part of the Grand Palace (photo @A. Segre, 2016)

\section{CUPOLAS BEFORE RESTORATION}

\subsection{Grand Palace and the Cupolas}

Two cupolas flanked the architectural composition of a three hundred meters-long façade of the Grand Palace on both sides (Fig. 2). Each cupola consisted of a dome crowned with a smaller cupola on a lantern. The restoration of the Peterhof ensemble after the war started with general works, restoration of fountains of the central part of the ensemble, and structural works on the Grand Palace. By 1956 the structure and facades of the building of the Grand Palace had been practically fully restored, according to the restoration project by architect V. Savkov, but its two cupolas were still missing.

\subsection{Specific difficulties}

Restoration of the cupolas was difficult because of their architectural importance, a significant loss of material and other restoration problems. One of the central problems was lack of precise documentation of the cupolas before the destruction. Abundance of the available visual documentation consisted mainly of photographs and historical artistic images. As this historic site was of great historical value, and very popular as well, there were many professional and other photographs of different objects from different points of view, while cupolas were among the iconic items. 


\subsection{Specific decisions}

Though before the destruction, the eastern cupola was fiveheaded (with five small cupolas on lanterns over the dome), in 1950 -s it was decided to restore it according to the original design of Rastrelli in the $18^{\text {th }}$ century (which had not been realised because of the intervention of the Empress) - with only one cupola on the lantern over the church part. This made the palace design strictly symmetrical, as it was conceived by Rastrelli. This decision was also influenced by economic reasons.

\section{RESTORATION OF CUPOLAS}

\subsection{Restoration approach}

Two of the main distinctive features of the restoration works in Peterhof were that all possible efforts were made to discover or reconstruct original technologies and materials; and then, to restore damaged original object and keep (or return) them to their original location, even if this demanded a difficult consolidation or other types of works. This approach allowed to define as "restoration" even such cases that might appear to an outsider's eye as "new reconstruction". Therefore, the in-depth knowledge of restoration work that actually took place is indispensable for an accurate analysis of this specific restoration project - either as an entire ensemble, or with focus on its specific parts or objects. It should be pointed out that the restoration outlined in this paper took place before the Venice Charter (The Venice Charter, 1964). However, the restoration approach applied in the Peterhof ensemble, was compatible with some of the modern principles of conservation, which originated from the late $19^{\text {th }}$ - early $20^{\text {th }}$ century developments in this area (The Athens Charter, 1931).

The restoration of two cupolas was undertaken in 1956-1957, starting from the restoration project documentation to its completion. The works were led by architect-restorer Boris Lobovikov, who was in those years head of the production department of Special Scientific-Production Restoration Workshops (SSPRW), and later, until 1979, the head of the restoration of the Peterhof architectural ensemble. This paper is based on his archive.

\subsection{D Geometry reconstruction}

The geometry reconstruction of the cupolas can be sub-divided into "macro"-geometry of the overall shape of domes, lanterns and cupolas, and "micro"-geometry of their decorative elements. In order to reconstruct the 3D shape of the cupolas, several steps were undertaken. First, the original pieces of the cupolas which had fallen into the debris of the ruined palace were searched for, sorted and studied. These efforts lasted in Peterfof through almost two decades after the war. Besides that, all available visual material was analysed. On the basis of these two sources of information a series of models of general shape of domes, and of the cupolas on lanterns were made in diverse scales, subsequently progressing from general form (e.g. scale 1:5 - Fig. 3) to partial detailed models (scale 1:1 - Fig. 4). Models were lifted to a height which was in scale compatible with each model, and studied and photographed from an up-toscale eye level. The photographs were then compared with the original photographs of cupolas before damages taken from the same points of view, which allowed for correcting the models, if needed. The first basic models were aimed at verifying the precise proportions of the general shape, and didn't include details (Fig.3). Larger scales models were based on the first models; they already included decoration elements, and often were focused on verifying a specific part of a cupola, or specific type of elements. The later models, unlikely the first monochromatic ones, included colour distinction as typical of the original colour scheme of the palace and its cupolas: greyish metal-covered roof (which included the domes) gilt details decoration elements, including garlands of the domes and elements of cupolas on lanterns.

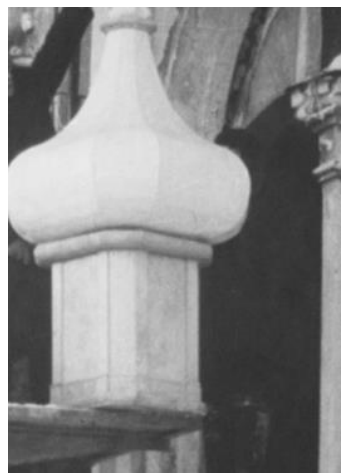

Figure 3. Basic model for a 3D shape reconstruction of a cupola on lantern. Scale 1:5, placed on scaffolding at a relative height (c) Boris Lobovikov archive

With regard to reconstruction of the original geometry of the decorative elements ("Micro"-geometry), the case was easier, because it could be based on the original parts and elements found on site. They were thoroughly studied and put on their original location on a model, e.g. a model of a corresponding part of a dome made to scale 1:1. 3D geometry of missing elements was reconstructed according to the same iterative image-model-image analysis process as of "Macro" geometry reconstruction. The missing elements were then modelled in clay, and incorporated in the same model of a 1:1 scale along with the original elements.

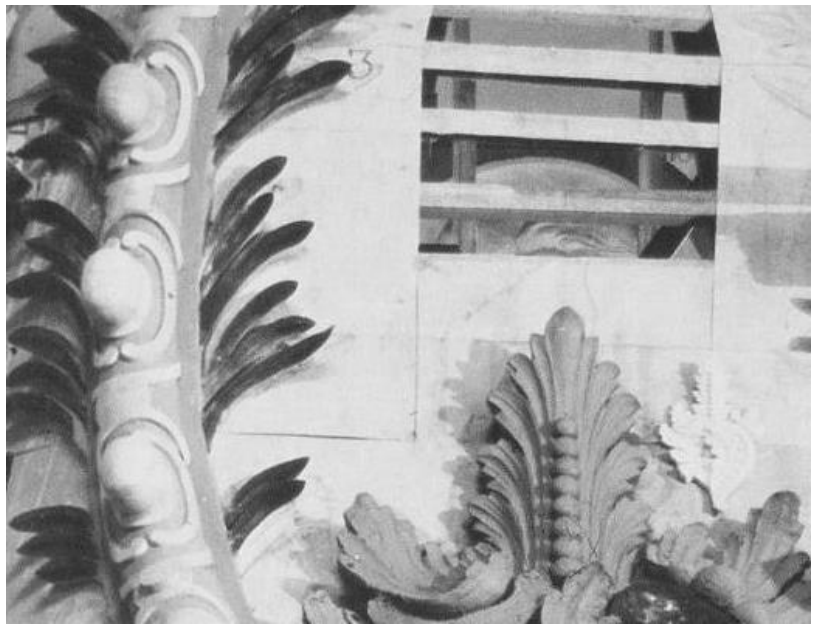

Figure 4. Fragment of a model combining the original and reconstructed decoration elements. Scale 1:1. (C) Boris Lobovikov archive

\subsection{Technologies and materials}

The material-technological process of restoring missing metal elements, e.g. parts of gilt copper garlands of the domes, - 
included the following stages: clay model, plaster cast, zinc form, final copper elements. Restoration/ reconstruction of cast sculptural elements was of a major importance and also involved clay models as one of the first steps of the process. Gilding work was undertaken in accordance with a scrupulous technological procedure of preparing targeted surfaces before gilding. This was based on the original technology and included a multi-step iterative process of applying layers of lacquerbased cover, drying, and a subsequent polishing of a lacquercovered surface.

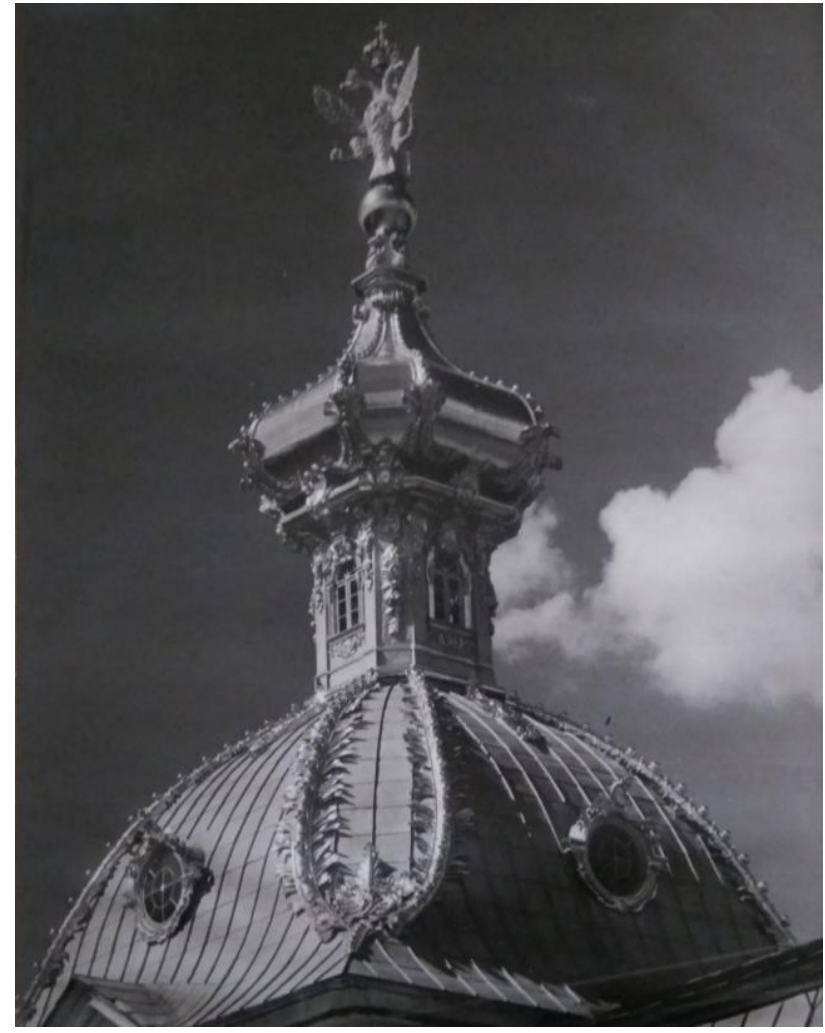

Figure 5. The cupola and the dome of the Western part of the Grand Palace after restoration (c) Boris Lobovikov archive

\subsection{Restoration approach in Peterhof}

Restoration work on the cupolas in Peterhof was undertaken before the formulation of modern conservation charters and documents (e.g. The Venice Charter, 1964; The Nara Document of Authenticity, 1994). However, some the main principles typical of the restoration school of Peterhof in 1950s are not far from modern international guidelines. These include documentation of restoration processes; preserving original fragments on their original location after their restoration; respect for and application of the original materials and techniques; and others.

The approach to restoration in Peterhof was compatible with many principles of The Venice Charter which was adopted in 1964, several years after the completion of cupolas. Restoration of Peterhof was aimed "to preserve and reveal the aesthetic and historic value of the monument"; it was based on "respect for original material and authentic documents" (Article 9). "Conjecture" had no place in the restoration of Peterhof, as the form before the destruction was always known. In this way, restoration in question was almost in complete harmony with Articles 9-13 of The Venice Charter (the chapter
"Restoration"), with one major exception: the distinction between the new and the old materials. Restoration work used the same materials and the same historic technologies that were applied to the original parts, and distinction between the original and the restored/ reconstructed parts was not visible. However, after the restoration of the interiors, each hall in the Grand Palace and other palaces contained an explanatory stand showing its state before restoration. Furthermore, knowledge and awareness of heavy damage of the Peterhof architectural ensemble and of its subsequent restoration was widely disseminated among the general public.

In general, Peterhof can be approached as a very complex spatial architectural integrity presenting a multi-level hierarchy of sub-objects, e.g. the entire ensemble, sub-ensembles, etc. For example, sub-ensemble of the central part of the complex includes the Grand Palace, the Grand Cascade, parterres, fountains and Voronihin Collonades. Each components of this sub-ensemble is a complex object in itself. In this case, reconstruction of a certain element of a sub-object can be seen as part of restoration work of an object of a higher hierarchic level.

A specific point should not be overlooked with regard to Peterhof restoration - a notable influence of French culture on Russian culture in $18^{\text {th }}-19^{\text {th }}$ centuries. It seems that this influence can be traced in some restoration approaches. For example, the decision to restore only one cupola on the lantern of the eastern part of the Grand Palace might be seen as a reflection of traces of a historical influence of Viollet-le-Duc (in the past the eastern part of the Palace was built from the beginning according to five-cupola scheme). However, unlikely some of Viollet-le-Duc's statements, this case was not restoration of an ideal situation that had never existed in the past, but rather of part of the architect's project planned by him but not realized (besides economic aspect of the restoration decision to restore one cupola instead of five). The specific subject of the French influence in restoration in Russia should be studied further.

\section{CONCLUSIONS}

\subsection{Digitization in research and preservation of historic non-digital 3D object reconstructions}

Questions and dilemmas on reconstruction of 3D geometry of heavily damaged or lost historical objects existed long before the development of Information and Communication Technologies (ICT) and their application to conservation of cultural heritage. Unlike the ease of digital collecting, analysing and visualising 3D data on geometry and materials of restoration objects, 3D geometry reconstruction before the computer era could only be achieved by making a physical model of the object. Any adjustment usually involved numerous versions of the model. This tedious and demanding process often produced rich restoration material of high level of complexity, as exemplified in this paper by the case study of restoration of the cupolas of the Grand Palace in Peterhof. Study of the available records of such material, aided by 3D reconstruction of restoration steps of the past restoration projects can allow for better understanding of methodologies and techniques of historic restorations, for discovering and learning from their achievements and mistakes. Targeted 3D digitizing and analysis of restoration archives can be an important step in study and preservation of the history of restoration (Recommendations, 2011). Reconstruction of the 
non-digital 3D objects reconstructions can add new dimensions to the modern and emerging ICT methodologies, basing on recent development in this area (Brumana et al. 2018a, 2018b; Previtali, 2018). Study of a combined approach to geometrical $3 \mathrm{D}$ reconstructions and technologies and materials applied in historic restorations can benefit from the advanced and emerging development, e.g. HBIM, and others, and might enrich ICT development in this area by posing innovative tasks.

\subsection{Visualization of historical 3D data on historical restoration projects}

Combined visualizing of different types and layers of 3D information on historic sites, besides its contribution to conservation experts and researchers, has an educational value (Banfi et al. 2018). Making this data accessible to visitors on historic sites with the aid of VR/AR allows them to understand the metamorphoses of historic monuments over time. Providing a widely accessible 3D data on historic restorations would make an important contribution to awareness and understanding of conservation/ restoration by general public, and subsequently to their understanding of cultural heritage and of the importance of its preservation. Furthermore, immersive learning, by combining 3D virtual interpretation of the modern and of the historical information with studying physical objects can significantly contribute to the visitors' understanding of historic buildings and sites (Hazan et al. 2017). Copyright, IPR, as well as adaptation of CIDOC standards provide multiple challenges with regard to diverse uses of public and private archives in history of restoration. Sufficient solutions for these and other problems will allow to build a Virtual 3D Museum/Hub of Restoration History.

\section{ACKNOWLEDGEMENTS}

This paper is dedicated to the memory of the restoration architect Boris Lobovikov who contributed more than twenty years of his professional work to the restoration of the Peterhof (Petrodvorets) ensemble of parks, palaces and fountains.

\section{REFERENCES}

Banfi F., Stanga C., Brumana R. (2018) A Digital Workflow for Built Heritage: From SCAN-to-BIM Process to the VR-Tour of the Basilica of Sant'Ambrogio in Milan. In: Ioannides M. et al. (eds) Digital Heritage. Progress in Cultural Heritage: Documentation, Preservation, and Protection. EuroMed 2018. Lecture Notes in Computer Science, vol 11196. Springer, Cham 10.1007/978-3-030-01762-0_28

Brumana R., Condoleo P., Grimoldi A., Landi A.G, Attico d., T., Banfi F. and Previtali M., (2018a)) HBIM Feeding Open Access Vault Inventory Through GeoDB HUB. In: Ioannides M. et al. (eds) Digital Heritage. Progress in Cultural Heritage: Documentation, Preservation, and Protection. EuroMed 2018. Lecture Notes in Computer Science, vol 11196. Springer, Cham 10.1007/978-3-030-01762-0_3, pp. 27-38

Brumana, R., Della Torre, S., Oreni, D., Cantini, L., Previtali M., Barazzetti, L., Banfi, F., (2018b). SCAN to HBIM-Post Earthquake Preservation: Informative Model as Sentinel at the Crossroads of Present, Past, and Future. In: Ioannides M. et al. (eds) Digital Heritage. Progress in Cultural Heritage: Documentation, Preservation, and Protection. EuroMed 2018. Lecture Notes in Computer Science, vol 11196. Springer, Cham 10.1007/978-3-030-01762-0_4
Hazan, S., Lobovikov-Katz, A., 2017. The Willing Suspension of Disbelief: The Tangible and the Intangible of Heritage Education in E-Learning and Virtual Museums. In: Ioannides M., Magnenat-Thalmann N., Papagiannakis G. (eds) Mixed Reality and Gamification for Cultural Heritage. Springer, Cham 10.1007/978-3-319-49607-8_22

Izmailov, M., 1909. Guide to Peterhof (Putevoditel po Petergofu/ Guide de Peterhof). St. Petersburg: T-vo R. Golike i Vil'borg

Lobovikov, B., 1989. Restoration of the Grand Palace in Peterhof (manuscript).

Michailov, B. (ed), 1963 Vseobshaya Istoria Arhitecturi (Golbal History of Architecture), Gosudarstvennoe Isdatelstvo Literaturi po Stroitelstvu, Arhitecture i Stroitelnim Materialam, Moskva

Previtali, M. \& Latre, M.Á., 2018. A brokered Virtual Hub approach for the generation of web applications based on historical maps, Appl Geomat (2018) 10: 453-472. 10.1007/s12518-018-0235-1

Recommendations, 2011. Commission Recommendation of 27 October 2011 on the digitisation and online accessibility of cultural material and digital preservation (2011/711/EU), Official Journal of the European Union 283/39

The Athens Charter for the Restoration of Historic Monuments, 1931. Adopted at the First International Congress of Architects and Technicians of Historic Monuments, Athens https://www.icomos.org/en/resources/charters-and-texts

The Nara Document on Authenticity, 1994. (ICOMOS) https://www.icomos.org/charters/nara-e.pdf

The Venice Charter., 1964. International charter for the conservation and restoration of monuments and sites, IInd International Congress of Architects and Technicians of Historic Monuments, Venice, 1964. https://www.icomos.org/charters/venice_e.pdf 